\title{
Breves relatos de uma bailarina gorda
}

\section{Stories of a fat ballerina}

\begin{abstract}
Jussara Belchior Santos
Bailarina gorda. Em seu trabalho solo Peso Bruto (2017) investiga sobre os tabus e preconceitos sobre as gordas. Mestra (2017) e Doutoranda em Teatro pela Universidade do Estado de Santa Catarina (UDESC) com a pesquisa Investigações pesadas. Pesquisadora da dança, diretora, assistente de direção, interlocutora e crítica em parceria com outras artistas. Integrou o elenco do Grupo Cena 11 Cia de Dança entre 2007 e início de 2018. Interessa-se poéticas e políticas de movimento e posicionamento através da dança jusbelchior@gmail.com - https://orcid/0000-0002-8592-6229
\end{abstract}

\section{Resumo}

Este texto apresenta uma coleção de fragmentos a respeito do fazer artístico-acadêmico da bailarina gorda Jussara Belchior. A escrita trata de questões que discutem e interseccionam a gordofobia como a criação coreográfica do trabalho solo Peso Bruto (2017), a noção de representatividade gorda, experiências de invenção e reflexão sobre os modos de fazer (arte e pesquisa), um referencial gordo que cruza diversos campos do conhecimento, saberes que se constituem pela proposição de que o pessoal é político, de Carol Hanisch e uma escrita bruta que se dá através de procedimentos da prática em dança da autora

Palavras-chave: Escrita e arte. Performatividade (Filosofia). Discriminação contra pessoas com sobrepeso. Performance (Arte).

\section{Abstract}

This text presents a collection of fragments about the artistic-academic research of fat ballerina Jussara Belchior. The writing deals with issues, discussions and intersections of the fat phobia such as the choreographic creation of the solo piece Peso Bruto (2017), fat representation, experiences of invention and reflection on the ways of creating (art and research), fat references that crosses several fields of knowledge, informations constituted by the proposition personal is political, by Carol Hanisch and a gross writing that takes place through the author's dance practice procedures.

Keywords: Writing and art. Performative (Philosophy). Discrimination against overweight persons. Performance art. 


\section{Mapa da gordura}

[ou Apresentação]

Esta é uma coleção de relatos, ensaios, contos, reflexões, listas e desabafos sobre um fazer artístico-acadêmico. Os pequenos textos tratam de coisas do passado, do presente e do futuro da pesquisadora. Não são fragmentos ligados por uma continuidade [nem temporal, nem argumentativa], tal formato permite uma leitura não linear, entre saltos, interrupções e vai e vem. Nesta experiência: a cor das páginas atua como forma de trazer unidade, de modo a abraçar uma pluralidade que não cabe apenas em um título generalista; as diferentes cores das letras são intervenções que marcam justificativas, reflexões e deboches que ocorreram durante a escrita e a formatação centralizada é escolhida por apresentar um texto gordo, cheio de curvas e dobras, como um corpo fora do padrão. O que une esses textos é o modo como as temáticas atravessam o corpo da autora. Da brutalidade do corpo e da escrita, da invenção de outros modos, da relação com o tempo e da dança em Peso Bruto. Questões que se entrelaçam e desdobram em problematizações de uma artista-acadêmica bailarina gorda.

\section{Tempo de artista-acadêmica ${ }^{1}$}

Já se foi o primeiro ano de doutorado. Agora já é tempo de pensar na qualificação, na escrita, nos livros e artigos empilhados na mesa ou salvos no computador. Em um ano muita coisa muda: as disciplinas influenciam, descobrem-se referências muito relevantes, pessoas cruzam nosso caminho sugerindo coisas e despertando dúvidas. A pesquisa ora trava, ora desata a andar loucamente. É preciso calma [talvez não seja só calma] para se organizar, para dar conta das leituras, do grupo de estudos, dos eventos acadêmicos, dos prazos e burocracias. Mas não é só isso, além da vida acadêmica, tem mais a vida de artista. Aliás, vida acadêmica (desta autora) só existe por causa da vida de artista. Então, administrar o tempo envolve também os ensaios, as apresentações, os projetos artísticos para encaminhar para editais, as fichas de inscrições de mostras e festivais, ler e responder e-mails de produção. Ufa! Agenda, é imprescindível aprender a usar a agenda [ou um aplicativo de tarefas, ou inventar algum

\footnotetext{
${ }^{1}$ Este texto não é (exatamente) escrito em primeira pessoa, mas escolhe-se pela escrita no feminino.
} 
método de anotação que ajude]. [Estou usando uma caderneta em que todos os dias anoto o que tenho que fazer. Ordeno as tarefas pelos prazos. Risco as coisas que finalizei. No dia seguinte crio uma lista repetindo itens não cumpridos e inserindo tarefas]. É preciso encarar o tempo. Tempo de artista. Tempo de acadêmica.

Não pelo tempo mas pelo acúmulo de funções, cabe aqui a proposição do artista e professor Ricardo Basbaum sobre a noção de artista-etc ${ }^{2}$. Antes, seria mais justo apresentá-lo segundo seus termos: o artista-etc Ricardo Basbaum propõe que artistas-etc tragam "para o primeiro plano conexões entre arte\&vida e arte\&comunidades, abrindo caminho para a rica e curiosa mistura entre singularidade e acaso, diferenças culturais e sociais, e o pensamento". Em outras palavras, ser artista-etc implica um modo de operar que está sempre a refletir e questionar sobre o seu fazer.

Artista-etc. Artista-acadêmica (ressaltando especificidades).

Administrar uma vida artístico-acadêmica é muito desgastante, porém, indispensável para algumas (como para esta autora). Tal complexidade se verifica na constante sensação de se estar vivendo duas vidas [ou etc vidas], mesmo que uma esteja implicada na outra. Um final de semana, por exemplo, pode se dividir entre descanso, estudos e tempo de lazer com familiares e amigos. Ou um final de semana pode se dividir entre tempo de viagem, montagem, aquecimento, apresentação e viagem de volta. É inegável (no caso desta artistaacadêmica) que a experiência de estar em cena colabora com as questões da tese em construção. Contudo, acumula-se o cansaço e a leitura. Por um momento tal acúmulo passa a ser sentido como uma traição [!!!]. É coisa demais, falta braço, falta corpo e falta tempo. Tem também a culpa [aquela aprendida na criação católica]. Culpa de gastar o tempo fazendo coisas desimportantes, culpa de empilhar a louça do café da manhã, almoço e janta na pia da cozinha, culpa de assumir muitos compromissos. (Os mesmos erros da época do mestrado).

Muitas apresentações, uma rotina de ensaios intensa, a sensação de trair a pesquisa acadêmica e de perder o controle do tempo. Vida dupla. Será que é possível levar essa vida dupla? Talvez o problema seja encará-la como dupla.

\footnotetext{
${ }^{2}$ BASBAUM, Ricardo. Amo os artistas-etc. Em: Políticas Institucionais, Práticas Curatoriais. Rodrigo Moura (Org.), Belo Horizonte, Museu de Arte da Pampulha, 2005.
} 
Este texto é um exercício para isso, para romper essas dualidades. É preciso reaprender a lidar com o tempo. Sim, há prazos a serem cumpridos, mas o tempo da produtividade artísticoacadêmica precisa encontrar o seu jeito. Não se trata apenas de passar algumas noites sem dormir, escrevendo durante as madrugadas. Não é sobre correr atrás do tempo perdido ou ganhar tempo. É sobre entender um outro tempo. Tempo de artista-acadêmica. [Não é o objetivo aqui aprofundar a reflexão sobre o tempo (duração ${ }^{3}$ e irreversibilidade ${ }^{4}$ ). Por ironia, não há tempo suficiente para isso]. Importa entender que para ser artista-acadêmica é necessário administrar o tempo em inconstâncias. Cada pessoa tem que descobrir suas variações, como atribuir prioridades e como cumprir prazos. É como entrar em um jogo de manipular e ser manipulado pelo tempo.

“45 minutos trabalhando em um parágrafo de 11 linhas e ainda assim ficar feliz, orgulhosx e aliviadx quando ele fica pronto.

escrever..."

Princesa Ricardo Marinelli

${ }^{3}$ Com Henri Bergson

${ }^{4}$ Com Ilya Prigogine 


\section{Entre os talheres e as panelas}

Ela lavava a louça, eu enxugava e guardava. Mas tinha uma espera entre isso. Entre os talheres e as panelas, sempre tinha espera. Nessa espera eu dançava. Apoiava os braços na beirada da pia e começava a trançar as pernas. Eu imaginava uma videodança quando eu nem sabia que isso existia. Um enquadramento só das pernas. Uma passada larga da perna direita para o lado. A perna esquerda se aproxima lentamente, arrastando os dedos do pé no chão. Mantenho os pés próximos. Pé direito inteiro no chão e pé esquerdo apoiado pelo metatarso, o calcanhar está fora do chão. O joelho esquerdo está um pouco dobrado. Flexiono ainda mais o joelho esquerdo arrastando o pé pela minha perna direita. Apoio o peito do pé esquerdo nas costas do joelho direito. Pauso. Desço rapidamente a perna esquerda e assim que meu pé esquerdo toca o chão levanto o pé direito. Rápida substituição da perna de apoio. Fico com a

perna direita suspensa a poucos centímetros do chão. Direciono o pé direito para trás na diagonal esquerda, cruzando as pernas. Croisé. Os dois pés estão apoiados no chão e as duas pernas esticadas. Dobro lentamente o joelho esquerdo para aumentar a distância entre as pernas. Allongé. Lanço meu peso para a perna direita me afastando da pia. Dou um passo para frente e pego a escumadeira. Seco-a e guardo-a na gaveta. Levanto o calcanhar esquerdo do chão. Inclino meu corpo reto para a direita. Continuidade e recomeço. A dança que descrevo aqui é memória inventada revisitando, não os passos que eu dançava em minha adolescência, mas um modo de dançar. Dança entrecortada pelo tempo e pelo pano de prato. Dançaatravessamento nas tarefas domésticas. (As tarefas domésticas realizadas pelas mulheres da casa!) 


\section{Brutalidade \\ [ou Representatividade gorda]}

Minha pesquisa parte da experiência em Peso Bruto ${ }^{5}$, um solo que trata do estranhamento do corpo gordo na dança. A proposta [da tese] é discutir alguns assuntos que têm se mostrado

${ }^{5}$ Peso Bruto (2017) é o trabalho solo da bailarina gorda Jussara Belchior, que parte do estranhamento causado pelo corpo gordo na dança. É uma dança de resistência que questiona os padrões de beleza e comportamento na tensão entre formato e embalagem, aparência e conteúdo. Uma dança que explora a materialidade do próprio corpo como caminho de empoderamento, que questiona as noções da gorda como subjetividade que opera um corpo errado, inadequado, não permitido, não belo e não desejável. Uma dança que articula diálogos entre o peso, o desejo, o apetite e a beleza, colocando em contraposição o controle e a brutalidade.

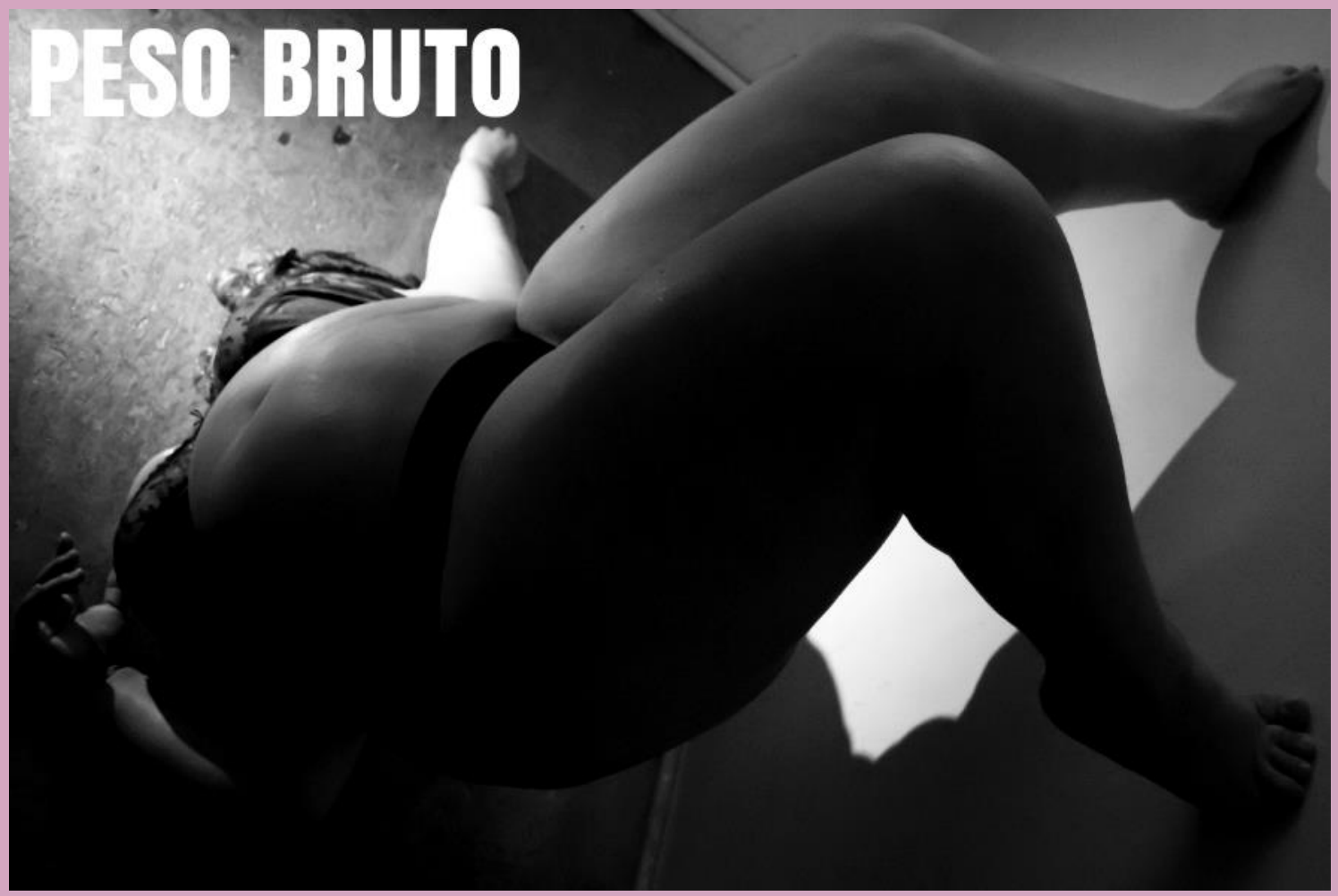

Arte gráfica de Marcos Klann em foto de Cassiana dos Reis Lopes para estreia de Peso Bruto, 2017.

Link teaser: https://www.youtube.com/watch?v=Ckbneej51Vc Link site: https://www.jussarabelchior.com/ 
chave, como representatividade gorda, empoderamento gordo e gordoativismo na arte. Para este texto trago referências de vilões e heróis de histórias em quadrinhos e animações (referências da minha juventude, que colaboraram no meu entendimento sobre o que é ser gorda) para problematizar a ideia de corpo gordo em nossa sociedade.

\section{- Hulk e o Coisa}

Após um acidente em seu laboratório de pesquisa, o cientista Bruce Banner ganha o poder de transformar-se em $\mathrm{Hulk}^{6}$, uma criatura verde, de força extrema e com o maior fator de cura entre os personagens da Marvel (maior que o do Wolverine!). No entanto, nem sempre é uma escolha de Banner transformar-se em Hulk. A grande criatura toma conta quando o cientista está furioso e quanto mais ele se irrita mais ele ganha força, causando assim muita destruição ao seu redor.

O Coisa ${ }^{7}$ é outro herói grande que age com sua força física e um certo descontrole. $\mathrm{O}$ integrante do Quarteto Fantástico se torna uma criatura mais dura que pedra. O curioso é que, embora Ben Grimm tenha adquirido seus poderes no mesmo acidente de radiação que seus parceiros, o Coisa é o único deles que não consegue alternar sua aparência entre humano e criatura. A problemática de seu aspecto monstruoso se intensifica quando o Coisa começa a namorar uma mulher cega. Ela é a única que não se incomoda em se relacionar com o homem de pedra, só ela é capaz de perceber beleza na materialidade daquele corpo que ela conhece pelo toque.

Embora Hulk e o Coisa sejam heróis com poderes incríveis, eles causam destruição por onde passam e reforçam, assim, a percepção de que esses corpos são incapazes de controlar suas ações. Além disso, a imagem desses personagens corpulentos e, consequentemente, destruidores afasta-os da noção de humano para aproximá-los do monstro. A desumanização dos corpos volumosos que perpassa essas narrativas acaba por reverberar nas relações com os corpos gordos do cotidiano.

\footnotetext{
${ }^{6}$ Hulk é um personagem de histórias em quadrinhos da Marvel, adaptado para animações e filmes. Foi criado por Stan Lee em 1962. Mais informações disponíveis em: https://marvel.fandom.com/ptbr/wiki/Bruce_Banner_(Terra-616).

${ }^{7}$ O Coisa é um personagem de histórias em quadrinhos da Marvel, integrante do Quarteto fantástico. Criado por Stan Lee em 1961; também adaptado para animações e filmes. Mais informações disponíveis em: https://www.legiaodosherois.com.br/lista/10-coisas-que-voce-precisa-saber-sobre-o-coisa.html.
} 


\section{- Rei do Crime}

Na direção contrária, o Rei do Crime ${ }^{8}$ exibe seu corpo volumoso com muito controle e precisão. Wilson Fisk trilhou seu caminho até se tornar o chefe do crime organizado na cidade de Nova Iorque. Sua força física não advém de nenhum poder sobre-humano, no entanto, ele é capaz de esmagar e arrancar partes do corpo de seus adversários. Sua ação é sempre pontual e controlada. Além disso, ele também exerce seu poder criando estratégias e delegando tarefas.

A força do Rei do Crime contribuiu durante o processo de Peso Bruto para pensar uma brutalidade que não estivesse condenada ao descontrole. Ainda que eu não seja uma vilã, minha dança navega entre a força, o controle, estratégias e sutileza.

\section{- Rose Quartz}

Como continuidade da pesquisa, interessa-me pensar em representatividade feminina gorda. A personagem Rose Quartz ${ }^{9}$ de Steven Universe, não fez parte das referências no processo de criação de Peso Bruto, mas articula modos de desdobrar tais entendimentos e provocações. Rose Quartz lidera uma rebelião em defesa do planeta Terra e passa a residir nele com seu grupo de pedras preciosas (alienígenas humanóides). A série se passa cinco mil e quinhentos anos depois dessa guerra e conta a história de Steven Universe, filho de Rose e do humano Greg Universe. Steven é meio humano e meio joia, ele herda não apenas os poderes de sua mãe, mas sua pedra mágica (aquilo que lhe dá sua forma física), ou seja, os dois não podem existir concomitantemente.

Além de uma gorda líder, Rose Quartz é compreensiva e desafiadora. Suas características se desvinculam dos estereótipos de gordos descontrolados, desajeitados e fracassados. Embora a personagem seja falecida, ela está sempre presente em Steven, que integra o grupo de joias protetoras dos humanos.

A série aponta ainda algumas questões de gênero interessantes. As personagens pedras mágicas têm o dom de se fundir e se tornar um ser mais forte. Garnet ${ }^{10}$, a atual líder do grupo, surge da fusão entre as pedras Rubi e Safira; estas, decidem viver em fusão pois encontram mais sentido em viver juntas. Garnet se une a Rose Quartz por ela ser uma líder que aceita a vida em união dessas joias.

\footnotetext{
${ }^{8}$ O Rei do Crime é um vilão de histórias em quadrinhos da Marvel, criado por Stan Lee em 1967; também adaptado para animações e filmes. Mais informações disponíveis em: https://marvel.fandom.com/ptbr/wiki/Wilson_Fisk_(Terra-616).

${ }^{9}$ Rose Quartz é personagem do desenho animado Steven Universe criada em 2013 por Rebecca Sugar. Mais informações disponíveis em https://stevenuniverso.fandom.com/pt-br/wiki/Rose_Quartz.

${ }^{10}$ Garnet é personagem do desenho animado Steven Universe criada em 2013 por Rebecca Sugar. Mais informações disponíveis em: https://stevenuniverso.fandom.com/pt-br/wiki/Garnet
} 
No decorrer dos episódios acontecem diversas situações que desviam da normatividade, o que se torna referência para as crianças, adolescentes e adultos que assistem ao desenho. $\mathrm{O}$ assunto da diversidade de corpos e comportamentos exposto nessa ficção é capaz de gerar outras formas de se lidar com o outro em nosso cotidiano.

\section{- Problematizando a representatividade}

É importante ressaltar a importância da representatividade gorda para que esses corpos não sejam mais invisibilizados, mas é preciso estar atenta para não se replicar um modelo de exclusão. Isto é, a gordura não pode ser representada sempre pelas mesmas pessoas, construindo assim um padrão aceito de gordura, excluindo corpos gordos (principalmente gordos maiores) que não se enquandram neste padrão. A representatividade tem que dar conta de uma diversidade, mas como fazer isso? Não tenho respostas, mas tenho experimentado algumas estratégias e conhecer outras pesquisas gordas tem me ajudado a pensar sobre isso.

\section{Gordas}

Em meu fazer artístico-acadêmico procuro estabelecer um cruzamento entre as questões que me atravessam, sem menosprezar um saber que não é necessariamente produzido na academia, que é mais comercial ou que é de cultura de massa.

Muito do material produzido na discussão antigordofobia está em blogs e vlogs que descrevem experiências pessoais \{a\}. Esses relatos são referências inegáveis para a construção de um campo de discussões que se expandem do pessoal para o coletivo ${ }^{11}$. Além disso, diversos campos do saber têm aproveitado o formato das redes sociais para ampliar o debate sobre o corpo gordo. Artistas, acadêmicas, ativistas, entre outras, estão produzindo e divulgando trabalhos e ações "de", "com" e "sobre" o corpo gordo $\{\mathbf{b}\}$.

Seguem abaixo algumas pessoas que tenho encontrado e acompanhado (na medida do possível). Esta listagem está longe de estar completa, a proposta aqui é de proporcionar uma rede, para fazer circular o saber gordo (termo da autora). Por mais que eu não dê conta de conhecer todas as pessoas gordas que estão ajudando na luta contra a gordofobia, é imprescindível compartilhar o trabalho daquelas às quais eu tenho tido acesso. Acompanhar

\footnotetext{
${ }^{11}$ Cf: The personal is political (1969), de Carol Hanisch.
} 
essas pessoas permite expandir cada vez mais essa rede, conhecendo mais e mais pessoas.

Enfim, este é também um convite para que a discussão sobre o corpo gordo não esteja restrita a gordos. (Siga pessoas gordas!)

\{a\} Canais de youtube que falam, entre outras coisas, sobre a experiência de ser gorda:

- Ju Romano, de Juliana Romano ${ }^{12}$;

- Bernardo Fala, de Bernardo Boechat ${ }^{13}$;

- Jessica Tauane (ex Gorda de boa), de Jessica Tauane ${ }^{14}$;

- Alexandrismos, de Alexandra Gurgel ${ }^{15}$;

- $\quad$ Tô de Bells, de Isabella Trad ${ }^{16}$;

- Tá querida, de Luiza Junqueira ${ }^{17}$

\{b\} Artistas, acadêmicas e ativistas gordas nas redes (instagram, facebook e youtube):

- Estudos sobre o Corpo Gordo Feminino, de Maria Luisa Jimenez Jimenez ${ }^{18}$;

- Tamanho Grande, de Agnes Arruda ${ }^{19}$;

- Pesquisa Gorda, de Maria Luisa Jimenez Jimenez e Agnes Arruda ${ }^{20}$;

- Manadatreme, de Coletivo Manada com Bruna Puntel, Jussara Belchior, Thais Putti e

\author{
Gaia Colzani ${ }^{21}$ \\ - virgietovar, de Virgie Tovar ${ }^{22}$; \\ - shooglet, de Shoog McDaniel ${ }^{23}$;
}

- fatbabesclubofcolumbus, de Krystal, Jae, Hannad e Elizabeth ${ }^{24}$;

- $\quad$ a_gorda_, de Ieza Karine ${ }^{25}$;

\footnotetext{
${ }^{12}$ Disponível em: https://www.youtube.com/channel/UC98OXziBFGRga3tQgUCOgcw

${ }^{13}$ Disponível em: https://www.youtube.com/channel/UCv1RFVLBWD-cqUwocOF2qKQ

${ }^{14}$ Disponível em: https://www.youtube.com/channel/UCORzZIM_fWAuCFc_TjEv9wg

${ }^{15}$ Disponível em: https://www.youtube.com/channel/UC2LQ5jMieMZjb5k5Gprp2JQ

${ }^{16}$ Disponível em:https://www.youtube.com/channel/UCMaROTUXVKxDuSToxZC1xSQ

${ }^{17}$ Disponível em: https://www.youtube.com/channel/UCVEVuanoMK9tGclfWLghaKw

${ }^{18}$ Disponível em: https://www.facebook.com/corpogordofeminino/

${ }^{19}$ Disponível em: https://www.youtube.com/channel/UC6pcxw-uzMM_XHnbWLas5aw

${ }^{20}$ Disponível em: https://www.youtube.com/channel/UCRS3IVpZCuo3vu9ZLxm8Tlg

${ }^{21}$ Disponível em: https://www.instagram.com/manadatreme/

${ }^{22}$ Disponível em: https://www.instagram.com/virgietovar/

${ }^{23}$ Disponível em: https://www.instagram.com/shooglet/

${ }^{24}$ Disponível em: https://www.instagram.com/fatbabesclubofcolumbus/

${ }^{25}$ Disponível em: https://www.instagram.com/a_gorda_/
} 
- Gordas sim chaqueta, coletivo (fundadoras: Diana Pulido, July Rosero, Cristina Uribe,

Paola Guiza e Ángela Quiceno) ${ }^{26}$;

- yrfatfriend, anônima ${ }^{27}$;

- shona_mcandrew, de Shona McAndrew ${ }^{28}$;

- Natália Barchet, de Natália Barchet ${ }^{29}$;

- historicalfatpeople, anônima ${ }^{30}$;

- collenmwerner, de Colleen M. Werner ${ }^{31}$;

- projetomulheresreais, de Maria Gabriela Calvano ${ }^{32}$;

- lailaalves, de Laila Alves ${ }^{33}$;

- olhardepaulina, de Milena Paulina ${ }^{34}$;

- Margens, de Jéssica Balbino ${ }^{35}$;

- curtase_, de Wise Primo, Lu Vasconcelos e Kat Silva ${ }^{36}$;

- artifats_collection, de Katy Kabloom ${ }^{37}$;

- rakeemc, de Rakeem Cunningham ${ }^{38}$.

"narrativas que transformam o mundo"

Jessica Balbino

${ }^{26}$ Disponível em: https://www.facebook.com/GordaSinChaqueta/

${ }^{27}$ Disponível em: https://www.instagram.com/yrfatfriend/

${ }^{28}$ Disponível em: https://www.instagram.com/shona_mcandrew/

${ }^{29}$ Disponível em: https://www.youtube.com/channel/UC_mbjTtN4xfpygfo9yjdbBw

${ }^{30}$ Disponível em: https://www.instagram.com/historicalfatpeople/

${ }^{31}$ Disponível em: https://www.instagram.com/colleenmwerner/

${ }^{32}$ Disponível em: https://www.instagram.com/projetomulheresreais/

${ }^{33}$ Disponível em: https://www.instagram.com/lailalalves/

${ }^{34}$ Disponível em: https://www.instagram.com/olhardepaulina_/

${ }^{35}$ Disponível em: https://www.youtube.com/channel/UCLbEXJPEK9ilVBWlOo8fgpg/about

${ }^{36}$ Disponível em: https://www.instagram.com/curtase_/

${ }^{37}$ Disponível em: https://www.instagram.com/artifats_collection/

${ }^{38}$ Disponível em: https://www.instagram.com/rakeemc/ 


\section{Biblioteca}

Às 6h03min o despertador toca. Sempre coloco números quebrados. Sabe, dormir mais cinco minutos às vezes parece pouco, e dormir mais dez minutos parece muito. Por que não dormir mais sete minutos? Soneca de sete minutos, nem muito, nem pouco. Gasto quase uma hora para sair de casa, sou lenta quando acordo. Pego o ônibus, desanimo com o trânsito. Chego na universidade, tomo um café com leite e vou para a biblioteca. O silêncio da biblioteca ajuda, o ar condicionado também. O terceiro andar da Biblioteca Central da UDESC nem é muito silencioso, aqui pode-se estudar em grupo. Poderia ficar no primeiro ou segundo andar, mas eu gosto das mesas aqui e da claridade que vem de fora. Além disso, a biblioteca está em reforma, silêncio não tem. Trabalho. Olho no relógio e já são quase 11 h30. É por isso que já estou com fome. Julgo o quanto consegui trabalhar, o quanto o esforço de estar aqui rendeu. Almoço. Mais um café ou uma coca-cola se estiver um dia quente. Volto para a biblioteca. Retomo os trabalhos. Vou até dar fome de novo ou até a cabeça fritar. Como alguma coisa. Volto para casa. Banho e cama.

\section{Jussarínes - inventando palavras, inventando modos}

Ines Saber ${ }^{39}$ e eu criamos um grupo de estudos em que nos juntamos para estar cada uma com sua pesquisa em 2015 ou 2016, quando ainda estávamos no mestrado ${ }^{40}$. No início este grupo teve poucos encontros, era difícil conciliar as agendas. Da minha parte, era difícil estar por muitas horas seguidas na biblioteca, já que eu ensaiava todos os dias da semana com o Grupo Cena 11 Cia de Dança ${ }^{41}$. No início de 2018, com meu afastamento da companhia, pensamos em estudar juntas para o processo seletivo do doutorado ${ }^{42}$. Estabelecemos um compromisso

\footnotetext{
${ }^{39}$ Ines Saber (de Mello) é Mestra (2017) e Doutoranda em teatro pela UDESC (2018). Integrante do coletivo artístico Mapas e Hipertextos em Florianópolis (2016-2017) e do Coletivo Crivo (2013-2017). Dedica-se a produções artísticas autônomas entre dança, performance, poesia e vídeo.

${ }^{40}$ Defendemos nosso mestrado no Programa de Pós-Graduação em Teatro na Universidade do Estado de Santa Catarina, em 2017.

${ }^{41}$ O Grupo Cena 11 Cia de Dança surgiu e é radicada na cidade de Florianópolis - SC desde 1991. Seus trabalhos de pesquisa e formação confluem teoria e prática no entendimento de dança e atravessam as definições de corpo tratando tecnologia como extensão e expansão do corpo.

${ }^{42}$ Processo seletivo no mesmo programa (PPGT - UDESC).
} 
rigoroso de dois encontros semanais. Foi um rico aprendizado e agora, aprovadas no programa, seguimos juntas nesse jeito que estamos inventando.

Apelidamos carinhosamente nosso grupo de Jussarínes. Às vezes também chamamos de Marjurínes, quando Marcos Klann ${ }^{43}$ nos acompanha. Algumas pessoas estranham que nos juntamos para não fazer, necessariamente, algo em comum. Às vezes estamos em atividades bem distintas, lendo, escrevendo e dançando coisas diferentes. Mas há troca, estamos disponíveis uma para a outra, em discussões sobre conceitos, ou sugestões de palavras, troca de referências e assim por diante.

Ines Saber não fez parte da equipe de Peso Bruto ${ }^{44}$, mas foi a primeira pessoa "de fora" a assistir ao ensaio do processo. Ela acompanha desde o início essa pesquisa sobre meu lugar de mulher e bailarina gorda. Com seu jeito de juntar referências e vontade de agir no mundo ela me incentiva e desafia a expandir meus limites. Nossa parceria tem se mostrado indispensável para mim. Acredito que eu também a provoque de alguma forma. Prezo muito nosso grupo de estudos não tão usual. Ainda que com o tempo tenhamos que reinventar outros jeitos de estarmos juntas, acho que já temos um pequeno tesouro, afinal, pesquisar é sobre inventar outros modos.

\footnotetext{
${ }^{43}$ É performer, bailarino, ator e iluminador. Mestre e Doutorando pelo PPGT - UDESC. Integrante do grupo

Cena 11, desde 2006. Ator e bailarino na O'ctus Cia de Atos (2001 - 2005). Criou: O que antecede a morte (2010) e Werwolf (2012). Sua pesquisa artística tem como foco as relações/tensões entre memória e coletividade.

${ }^{44}$ Ficha técnica de Peso Bruto:

Criação, produção e dança: Jussara Belchior. Interlocução: Soraya Portela.

Dramaturgia: Anderson do Carmo.

Trilha Sonora: Dimitri Camorlinga

Figurino: Joana Kretzer Brandenburg

Iluminação e Design Gráfico: Marcos Klann

Fotografia do Processo Criativo: Cassiana dos Reis Lopes

Registro em Vídeo: Cristiano Prim
} 


\section{Escrita bruta}

Pensar sobre a escrita de minha pesquisa tem sido um exercício desde que comecei a cursar o doutorado. Tenho experimentado uma escrita mais ensaística, organizada em fragmentos (como faço neste texto) que parte da descrição de situações para gerar a reflexão e cruzar referências. Escrevo, principalmente, a partir das conversas que tenho com o público após as apresentações do meu trabalho solo. Sinto que este formato é justo com a temática de minha pesquisa, que vem da prática para a academia. Tenho observado que em diversos campos do saber a reflexão sobre o corpo gordo tem sido realizada a partir de relatos pessoais. Através desses relatos é possível perceber que os corpos gordos sofrem opressões estruturais. Ao compartilharem suas histórias, as pessoas gordas compreendem que não estão sozinhas e que outras pessoas passam pelas mesmas dificuldades e preconceitos. Penso que meu exercício enquanto artista-acadêmica é de fazer esse percurso, do pessoal para o coletivo, tanto em cena quanto na escrita.

Para expandir o debate sobre o corpo gordo é preciso evidenciar a forma como esses corpos são invisibilizados, patologizados e excluídos do convívio social. Compartilho histórias na expectativa de que ao relacioná-las a outros pensamentos seja possível engordurar o mundo. Assim como em Peso Bruto, procuro trabalhar uma brutalidade diferente em minha escrita acadêmica. Uma escrita bruta que sabe se moldar aos espaços, sabe inventar seus espaços e fazer caber. Afinal, é assim que nós gordos nos movemos no dia a dia.

\section{Referências em cruzamento}

A usual lista de referências no final do texto não se adequa ao formato proposto aqui. A independência das escritas apresentadas permite que as referências sejam observadas em seus contextos de reflexão. O saber gordo que se constrói aqui (aqui e na continuidade da minha pesquisa de doutorado) entrelaça-se com diversos campos do conhecimento. Sejam referências no universo acadêmico, dos conteúdos pessoais produzidos para redes sociais ou

de saberes cotidianos. Portanto, para encontrar as referências é preciso engordurar-se. 


\section{REFERÊNCIAS}

BELCHIOR SANTOS, J. Jussara Belchior. Florianópolis, 2018. Website Jussara Belchior. Disponível em: https://www.jussarabelchior.com/. Acesso em: 01 set. 2019. 